\title{
A High-Performance Electrode Based on Reduced Graphene Oxide/Lignosulfonate/Carbon Microspheres Film for Flexible Supercapacitors
}

\author{
Ruquan Ren, Yan Zhong, and Yongming Fan * \\ Reduced graphene oxide (RGO) flexible film pillared with lignosulfonate \\ (LS) and carbon microspheres (CM) was fabricated via a facile vacuum- \\ filtration process to serve as a high-performance electrode material for \\ supercapacitors. Composite electrodes comprising graphene and \\ biomass materials have the advantages of being flexible, lightweight, \\ cheap, and environmentally friendly. The addition of LS and CM between \\ the RGO layers mitigated the self-restacking of reduced graphene oxide \\ flakes. Composite film electrode displayed a high specific capacitance of \\ $641 \mathrm{mF} \mathrm{cm}^{-2}$ at $0.2 \mathrm{~mA} \mathrm{~cm}^{-2}$, which was much higher than that of the RGO \\ film $\left(117.9 \mathrm{mF} \mathrm{cm}^{-2}\right)$. The present findings indicate a great potential of the \\ graphene films composited with biomass materials in fabricating flexible \\ supercapacitor electrodes.
}

DOI: 10.15376/biores.17.1.1729-1744

Keywords: Graphene; Lignosulfonate; Carbon microspheres; Supercapacitors

Contact information: Key Laboratory of Lignocellulosic Chemistry, College of Material Science and Technology Beijing Forestry University, Beijing, 100083, China;

* Corresponding author: fanym@bjfu.edu.cn

\section{INTRODUCTION}

Graphene has great potential as a flexible supercapacitor electrode (Gao and Duan 2015; Li et al. 2017), due to its high surface area $\left(2630 \mathrm{~m}^{2} \mathrm{~g}^{-1}\right.$ in theory) and outstanding electrical conductivity. Assembly of graphene into functional macroscopic objects, such as quantum dots, fibers, films, hydrogels, and other complex architectures has triggered great attention in the fields of energy storage composite materials (Maiti et al. 2014). Graphene can be applied in the fabrication of flexible self-standing films and directly used as electrodes without any support. Unfortunately, graphene sheets tend to agglomerate and restack to form multi-layered graphene, even graphite layers, due to van der Waals interactions, which results in the decreasing of the specific surface area (Zhao et al. 2011; Wang et al. 2012; Xu et al. 2012; Zhao et al. 2014; Sekar et al. 2015; Liu et al. 2018). Many studies have been done recently that focus on avoiding the stacking effect. For example, the introduction of wrinkles into the graphene layers (Yan et al. 2012; He et al. 2016), intercalation of nano-spacers between the graphene sheets, and the promotion of diffusion of graphene flakes were adapted to prevent the aggregation or stacking of the graphene flakes (Díez et al. 2019). The different carbon materials such as carbon quantum dots (0D) (Dang et al. 2016; Unnikrishnan et al. 2016; Zhang et al. 2017; Feng et al. 2018; Xu et al. 2020), carbon nano tube (CNT) (1D) (Yu and Dai 2009; Beidaghi and Wang 2012; Chen et al. 2013; You et al. 2013; Sun et al. 2014), and activated carbon (AC) (3D) (Xu et al. 2017) have been tried as spacers in the fabrication of graphene-based supercapacitors 
to facilitate the accessibility of electrolyte ions. Composite electrode materials with various fillers have been introduced into the supercapacitor to achieve the high performance. For example, an electrode with a three-dimensional structure has been fabricated by the addition of activated carbon, carbon nano tube, and reduced graphene oxide (RGO), which displayed a high specific capacitance of $101 \mathrm{~F} \mathrm{~g}^{-1}$ at a density of $0.2 \mathrm{~A} \mathrm{~g}^{-1}$ (Li et al. 2018); a freestanding ternary composite film electrode of $\mathrm{CNT}, \mathrm{MnO}_{2}$, and graphene sheet with the specific capacitance of $486.6 \mathrm{~F} \mathrm{~g} \mathrm{~g}^{-1}$ has been used in the fabrication of a flexible supercapacitor (Jin et al. 2013).

The dispersion of graphene-based materials is challenging in the preparation of composites. Lignosulfonate, a main by-product in the acidic sulfite pulping process, has aroused wide interest due to its features of low cost and availability as a surfactant resource (Nagaraju et al. 2014; Zhao et al. 2015; Rębiś and Milczarek 2016; Xiong et al. 2016; Peng et al. 2019; Wu and Zhong 2019). Li et al. (2017) reported a novel metal-free flexible supercapacitor based on lignosulfonate functionalized graphene hydrogels with an impressive specific capacitance of $432 \mathrm{~F} \mathrm{~g} \mathrm{~g}^{-1}$ in aqueous electrolyte; $\mathrm{Xu}$ et al. (2020) produced a composite hydrogel supercapacitor electrode material with RGO and graphene quantum dots (GQDS), and the highly porous structure and active sites of GQDS resulted in an excellent electrochemical performance. Zhao et al. (2015) fabricated a nitrogendoped graphene for supercapacitor electrode material with in-plane porous structure with lignosulfonate and graphene oxide in the presence of urea; the nanoporous structure with doped-nitrogen endowed the composite material with supercapacitance up to $170 \mathrm{~F} \mathrm{~g}^{-1}$. The composite material of sodium lignosulfonate and graphene was also used in the fabrication of a sensor material. Chen et al. (2018) reported a thin-film humidity sensor, in which the sodium lignosulfonate and graphene were used as the moisture sensing layer and the conductive layer. Lignosulfonate can be used as the efficient dispersant for stabilizing the suspension of graphene oxide, but it also can introduce pseudocapacitance on the composite films. As a result, the stacking of graphene sheets can be avoided, and the capacitance performance of the materials can be improved. So far, little has been reported about the attempts using lignin derivatives as spacers in the fabrication of graphene-based electrode. Herein, the current authors present a metal-free composite film, composed of intercalated porous carbon microspheres, lignosulfonate, and RGO, for flexible supercapacitor material with high specific capacitance. In order to achieve the isolated RGO sheets and facilitate the formation of high specific area film for the supercapacitor electrode, the porous carbon microspheres, originated from chitosan, were uniformly dispersed between reduced graphene oxide nanosheets. The lignosulfonate was used as dispersant and pillared agents of graphene flakes. The composite film produced in this work exhibited excellent capacitance performance and rate performance, as self-standing electrodes for supercapacitors due to the smaller diffusion resistance.

\section{EXPERIMENTAL}

\section{Materials and Chemicals}

The graphene oxide (GO) was prepared according to a modified Hummers' method (Hummers and Offeman 1958). Chitosan (low viscosity: <200 mPa.s), lignosulfonate and $\mathrm{KOH}$ (GR, 95\%) were purchased from Shanghai Macklin Biochemical Co., Ltd. (Shanghai, China); $\mathrm{HCl}$ (AR, 36\% to 38\%) was purchased from Peking Reagent (Beijing, China); 
hydrazine hydrate (AR, 80\%) was purchased from Shanghai Aladdin Biochemical Technology Co., Ltd. (Shanghai, China).

\section{Synthesis of Carbon Microspheres (CM)}

For the synthesis of CM, 3.0 g chitosan (Shanghai Macklin Biochemical Co., Ltd. low viscosity: $<200 \mathrm{mPa}$.s) was evenly dispersed into $100 \mathrm{~mL} 1 \mathrm{M} \mathrm{HCl}$ aqueous solution by magnetic stirring. The mixture was then transferred into a $150 \mathrm{~mL}$ Teflon-lined stainless-steel autoclave and heated to $210^{\circ} \mathrm{C}$ for $20 \mathrm{~h}$ (Wei et al. 2021). After cooling to room temperature, the black solid product was collected and washed with ethanol and distilled water until achieving neutrality. The solid product was then thoroughly ground with an equal weight of $\mathrm{KOH}$ for $15 \mathrm{~min}$, and a certain amount of deionized water was added and stirred for $1 \mathrm{~h}$. Then, the mixture was placed in a tube furnace at $600{ }^{\circ} \mathrm{C} 1 \mathrm{~h}$ for carbonization and at $800{ }^{\circ} \mathrm{C}$ for $2 \mathrm{~h}$ for activation under $\mathrm{N}_{2}$ atmosphere. After cooling to room temperature, the activated samples were washed using $1 \mathrm{M} \mathrm{HCl}$ and deionized water respectively to reach a neutral $\mathrm{pH}$. The $\mathrm{CM}$ product was obtained after drying in an oven at $105{ }^{\circ} \mathrm{C}$ for $4 \mathrm{~h}$ overnight.

\section{Synthesis of RGO/LS/CM Film Electrodes}

First, $5 \mathrm{~mL}$ of GO solution $\left(2 \mathrm{mg} \mathrm{mL}^{-1}\right)$ and $50 \mathrm{mg}$ lignosulfonate were mixed in $45 \mathrm{~mL} \mathrm{~N}, \mathrm{~N}$-dimethylformamide (DMF) to obtain a GO/LS suspension. The preparation procedure of RGO/LS/CM composite film is depicted in Fig. 1. After sonication for $0.5 \mathrm{~h}$, GO was reduced with hydrazine hydrate $(80 \%)$ with the weight ratio of hydrazine hydrate to GO being about 7:10 in the suspension. After stirring in a water bath $\left(95^{\circ} \mathrm{C}\right)$ for $2 \mathrm{~h}$, a desired quality of CM (1 mg, $3 \mathrm{mg}$, and $5 \mathrm{mg}$ ) was added into the mixed solution, and the composite films RGO/LS/CM were made by vacuum filtration on the membrane $(50 \mathrm{~mm}$ in diameter and pore size $0.22 \mu \mathrm{m})$. The obtained film was referred to as RGO/LS/CM1, $\mathrm{RGO} / \mathrm{LS} / \mathrm{CM} 3$, and RGO/LS/CM5, corresponding to CM 1, 3, and $5 \mathrm{mg}$, respectively. For reference, the RGO and RGO/LS films were made with the same process. The schematic image of RGO/LS/CM film is shown in Fig. 2.

\section{Characterization}

The morphologies of the cross-section of the films were observed using an SEM (Gemini300, ZEISS, Jena, Germany). The energy dispersive X-ray spectra (EDS) were collected on Oxford MAX-50 (Oxford, UK). The Raman spectrum was recorded on a Thermo DXR2xi (Waltham, MA, USA) with an excitation laser beam wavelength of 633 $\mathrm{nm}$. The XPS analysis was performed in a Thermo Fisher K-Alpha using Al Ka X-ray source $(1486.6 \mathrm{eV})$ operating at $100 \mathrm{~W}$. The specific surface areas and porous size distribution were determined from the corresponding $\mathrm{N}_{2}$ adsorption-desorption isotherms obtained at $-196{ }^{\circ} \mathrm{C}$ with an automatic instrument (ASAP2020, Micromeritics, Norcross, GA, USA), The specific surface areas and porous size distribution were calculated from the Brunauer-Emmett-Teller (BET) method and the Barrett-Joyner-Halenda (BJH) method, respectively.

\section{Electrochemical Measurements}

Electrochemical measurements were performed using a three-electrode system. The fabricated film was cut into $1 \times 1 \mathrm{~cm}^{2}$ samples as the working electrodes. The electrochemical workstation (CHI 660E) was used for the measurement of cyclic voltammetry $(\mathrm{CV})$, galvanostatic charge/discharge (GCD), and electrochemical impedance 
spectroscopy (EIS) in $1 \mathrm{M} \mathrm{H}_{2} \mathrm{SO}_{4}$ electrolyte with saturated calomel electrode (SCE) as a reference electrode and platinum as a counter electrode. The scanning rate was 5 to 100 $\mathrm{mV} \mathrm{s}^{-1}$ for the CV experiments with a working potential window of 0 to $1 \mathrm{~V}$. The area specific capacitance and the specific capacitance was calculated by GCD experiments using the follow equation,

$$
\begin{aligned}
& C=I \Delta t / S \Delta V \\
& C_{s}=I \Delta t / m \Delta V
\end{aligned}
$$

where $C$ is the area specific capacitance $\left(\mathrm{C}, \mathrm{mF} \mathrm{cm}^{-2}\right)$ of film electrode, $C_{S}$ is the specific capacitance $\left(\mathrm{Cs}, \mathrm{F} \mathrm{g} \mathrm{g}^{-1}\right), I$ is the discharging current, $S\left(\mathrm{~cm}^{2}\right)$ is surface area of the working electrode, $m(\mathrm{~g})$ is the effective mass of electrode material, and $\Delta V$ is the voltage of the scanning window.
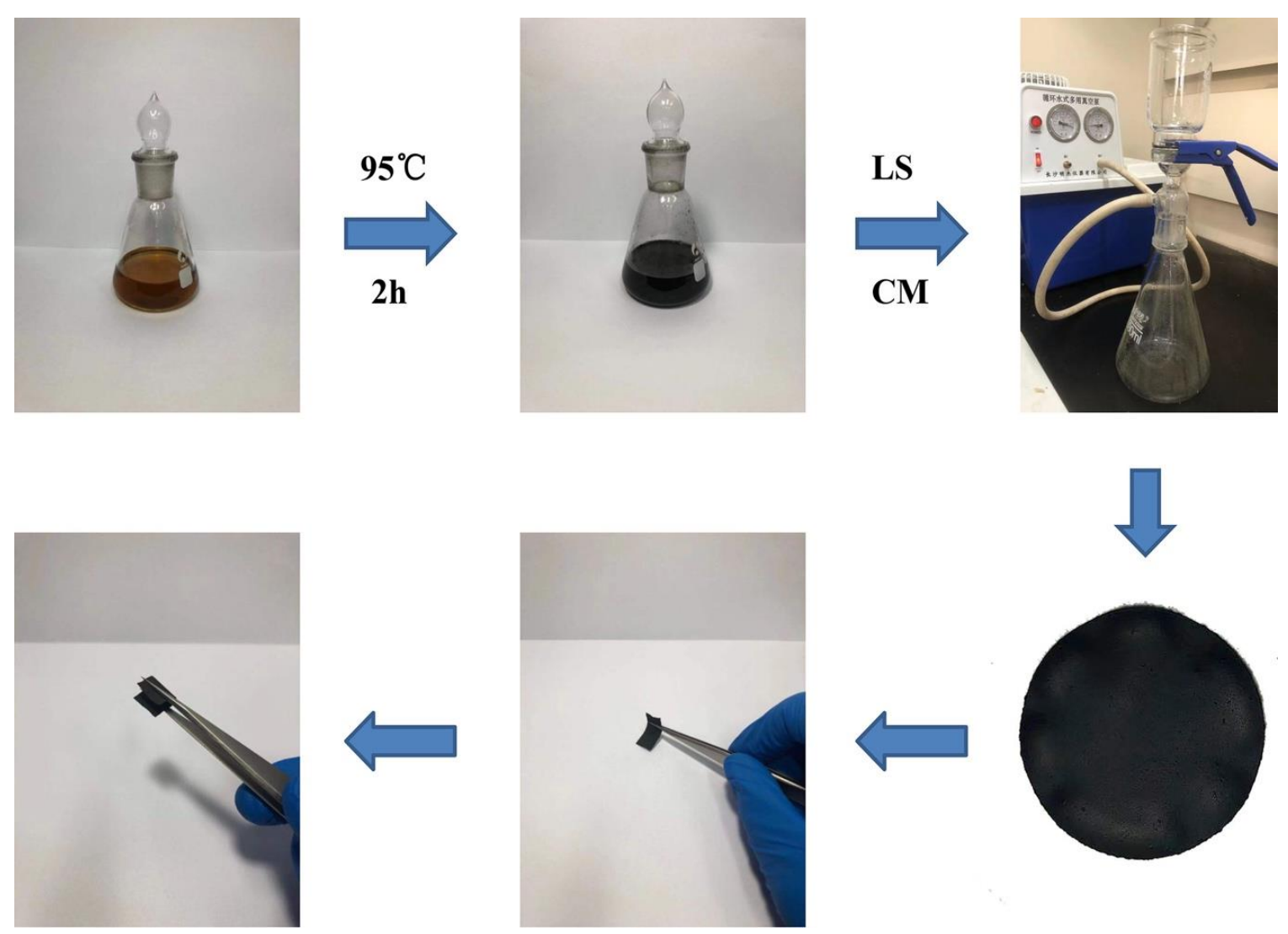

Fig. 1. Illustration of the preparation procedure of RGO/LS/CM film 

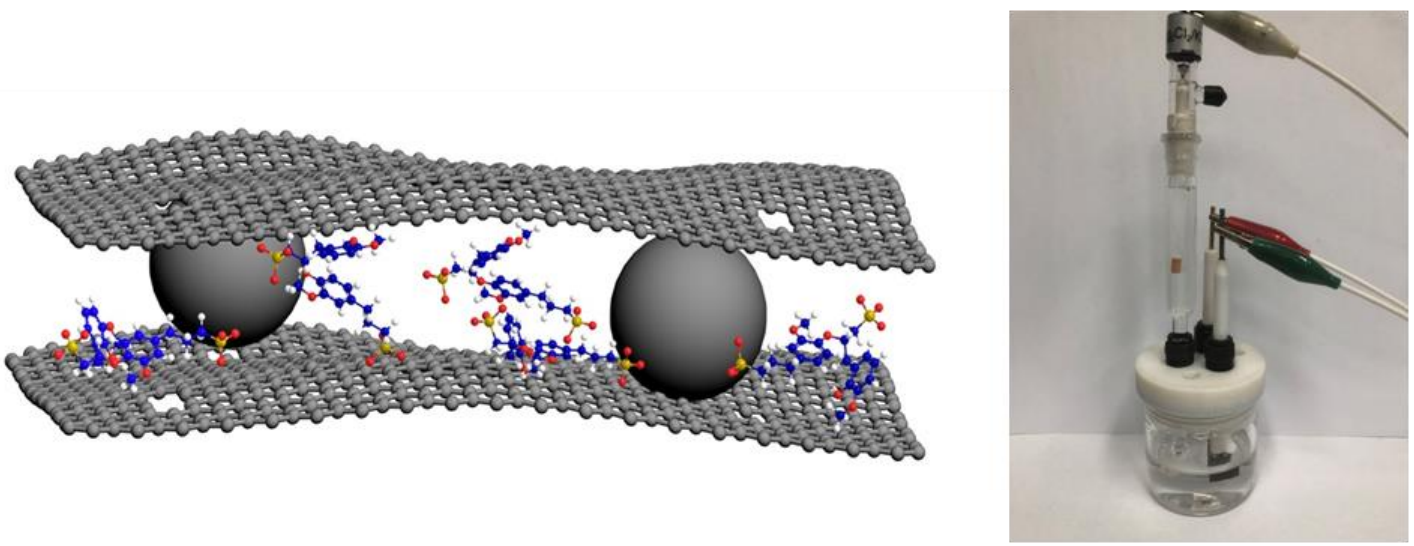

Fig. 2. Schematic image of RGO/LS/CM film

\section{RESULTS AND DISCUSSION}

\section{Characterization of $\mathrm{CM}$ and the Film Electrodes}

The microscopic morphologies of CM derived from chitosan are shown in Fig. 3.
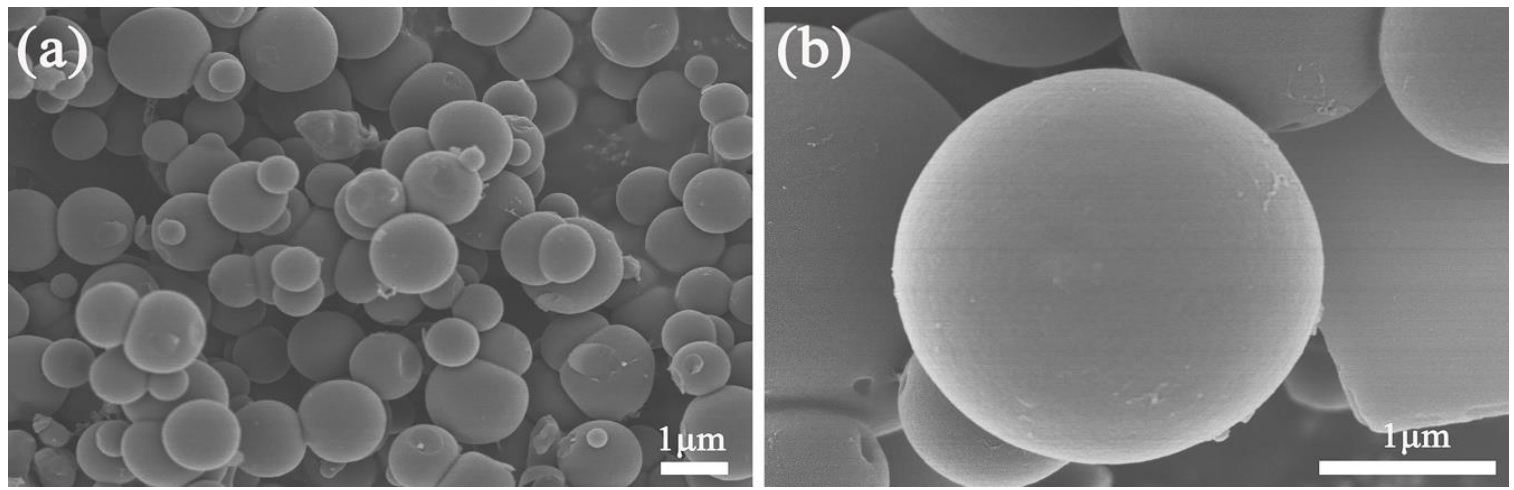

Fig. 3. SEM images of CM 

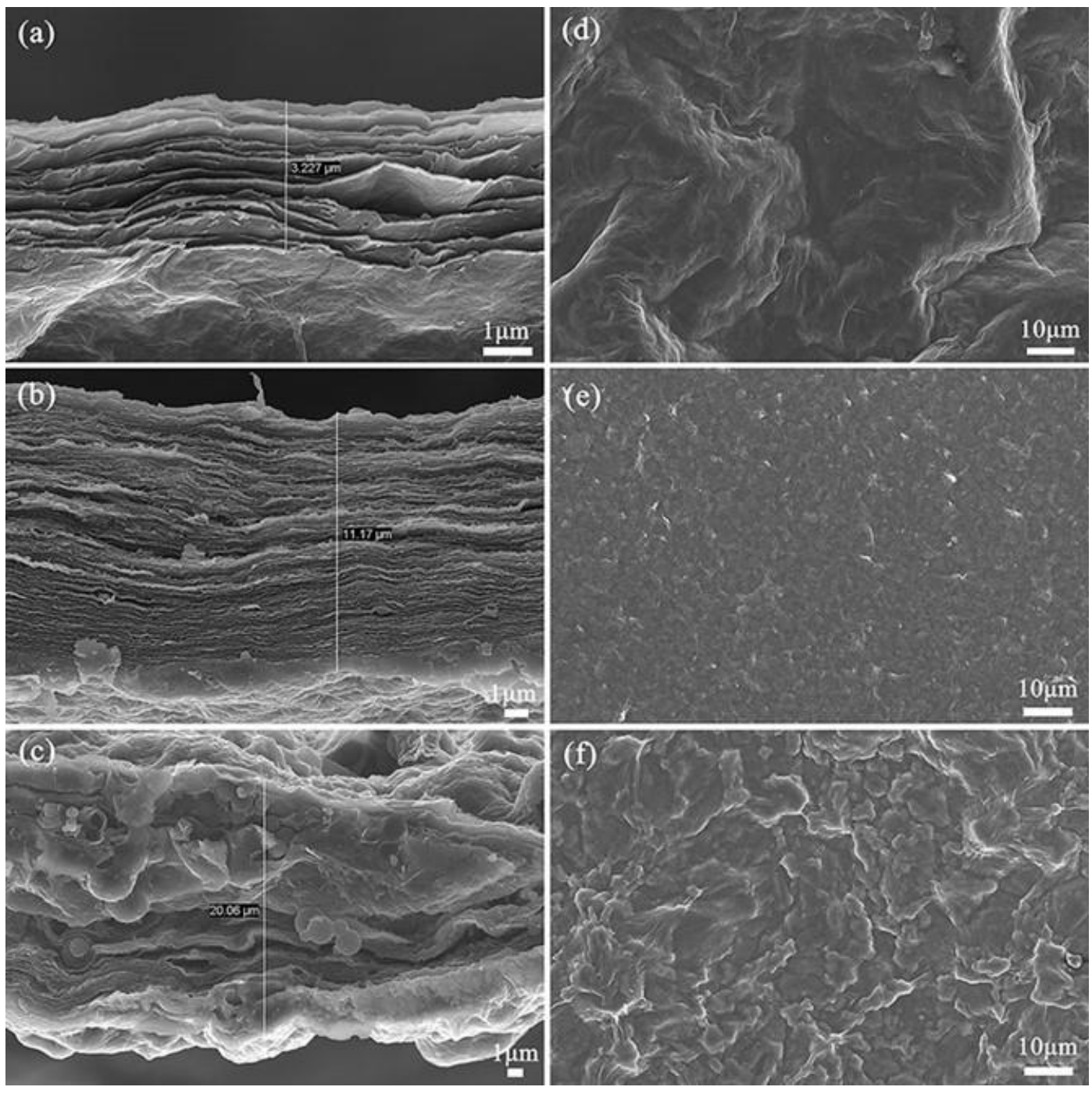

Fig. 4. Cross-sectional SEM images of RGO (a), RGO/LS (b), and RGO/LS/CM5 (c). SEM images of RGO (d), RGO/LS (e), and RGO/LS/CM5 (f) surface morphologies

It is noteworthy that $\mathrm{CM}$ exhibited a regular spherical structure with a diameter of $400 \mathrm{~nm}$ to $1.5 \mu \mathrm{m}$. In addition, there was no obvious pore structure on the surface of the carbon microspheres, which indicated that the CM sample mainly possessed a microporous structure. This result was consistent with the BET test.

Figure 4 shows the open layered section structure and the surface topography of composite films. Lignosulfonate is a dispersant with hydrophobic phenylpropane skeleton and hydrophilic groups. The hydrophobic skeleton is combined with a hydrophobic plane of RGO sheets by $\pi-\pi$ conjugation during the process of vacuum filtration. As shown in Fig. 4, the RGO/LS film displays a smooth surface (Fig. 4e), which was due to the addition of lignosulfonate nanosheets. This is because LS can have intercalation between RGO sheets and make the RGO sheets more orderly. The thickness of the RGO film was about $3.2 \mu \mathrm{m}$, while the thickness of the RGO/LS and RGO/LS/CM5 films were about $11.2 \mu \mathrm{m}$ and $20 \mu \mathrm{m}_{2}$ respectively, in the same quality of GO. Meanwhile, it can be observed that $\mathrm{CM}$ was evenly distributed between the RGO sheets from Fig. 4c. These details reveal that the presence of LS and CM increased the interlayer spacing of the RGO composite film, which benefited from the infiltration and transmission of electrolyte. In addition, the 
energy-dispersive X-ray spectroscopy (EDS) result, which is shown in Fig. 5, illustrated that the S contents (wt \%) of sample RGO/LS and RGO/LS/CM5 were 12\% and 6\% more than that of sample RGO (1.72\%). Combined with the result of SEM imaging, it can be confirmed that the LS successfully intercalated into the interlayer of RGO.

The XPS spectra of $\mathrm{C} 1 \mathrm{~s}$ peaks for composite films are shown in Fig. 6. For RGO film, three peaks at 284.8, 285.92, and $286.88 \mathrm{eV}$, could be assigned to $\mathrm{C}-\mathrm{C}, \mathrm{C}-\mathrm{O}$, and $\mathrm{C}=\mathrm{O}$ bonds, respectively (Yang et al. 2009; Qian et al. 2011; Al-Gaashani et al. 2019). The intensity of $\mathrm{C}-\mathrm{O}$ and $\mathrm{C}=\mathrm{O}$ peaks of $\mathrm{RGO} / \mathrm{LS}$ film and $\mathrm{RGO} / \mathrm{LS} / \mathrm{CM} 5$ film increased compared with RGO film. The main reason for this was the addition of lignosulfonate, which can introduce massive oxygen-containing groups. The same situation from the whole XPS spectra of all samples, which is shown in Fig. 7a, the $\mathrm{C} / \mathrm{O}$ atomic\% of sample RGO/LS (3.5) and RGO/LS/CM5 (3.44) was obviously lower than that of sample RGO (7.1). Moreover, the small peaks (S 2p) that appeared in the RGO/LS and RGO/LS/CM5 also confirmed the presence of LS. The Raman spectra (Fig. 7b) showed the D and G bands of all composite films, which were centered at $\sim 1350$ and $\sim 1580 \mathrm{~cm}^{-1}$, respectively. The intensity ratio of $\mathrm{D} / \mathrm{G}$ band $\left(I_{\mathrm{D}} / I_{\mathrm{G}}\right)$ is commonly used to measure the disorder degree or defects of carbonaceous structures (Ferrari et al. 2006; Malard et al. 2009). Compared with RGO film, the $I_{\mathrm{D}} / I_{\mathrm{G}}$ ratio of RGO/LS film decreased from 1.42 to 1.08 , and it was suggested that the LS between the graphene sheets did not introduce covalent defects but formed noncovalent interaction (hydrogen bonds and $\pi-\pi$ conjugation), which resulted in a better combination and excellent mechanical properties. However, the $I_{\mathrm{D}} / I_{\mathrm{G}}$ ratio of RGO/LS/CM5 film was 1.22, and it might be suggested that the CM had a higher degree of graphitization.

The porous structure of all samples was analyzed by $\mathrm{N}_{2}$ adsorption/desorption isotherms at $-196{ }^{\circ} \mathrm{C}$. From $\mathrm{N}_{2}$ adsorption isotherms shown in Fig. 8a, for the sample $\mathrm{CM}$ and $\mathrm{RGO} / \mathrm{LS} / \mathrm{CM} 5$, there was a sharp increase in the amount of $\mathrm{N}_{2}$ adsorbed at the 0 to 0.1 relative pressures range. This characteristic revealed that the CM mainly possessed a microporous structure (pores with a size $<2 \mathrm{~nm}$ ) (Shang et al. 2015). A similar characteristic of pore size distribution is shown in Fig. 8b. Moreover, Table 1 shows the detailed information regarding the physical properties of all samples, compared with the samples, RGO, RGO/LS, and RGO/LS/CM5 film showed the larger specific area and pore volume which was due to the addition of LS and CM. 


\section{bioresources.com}

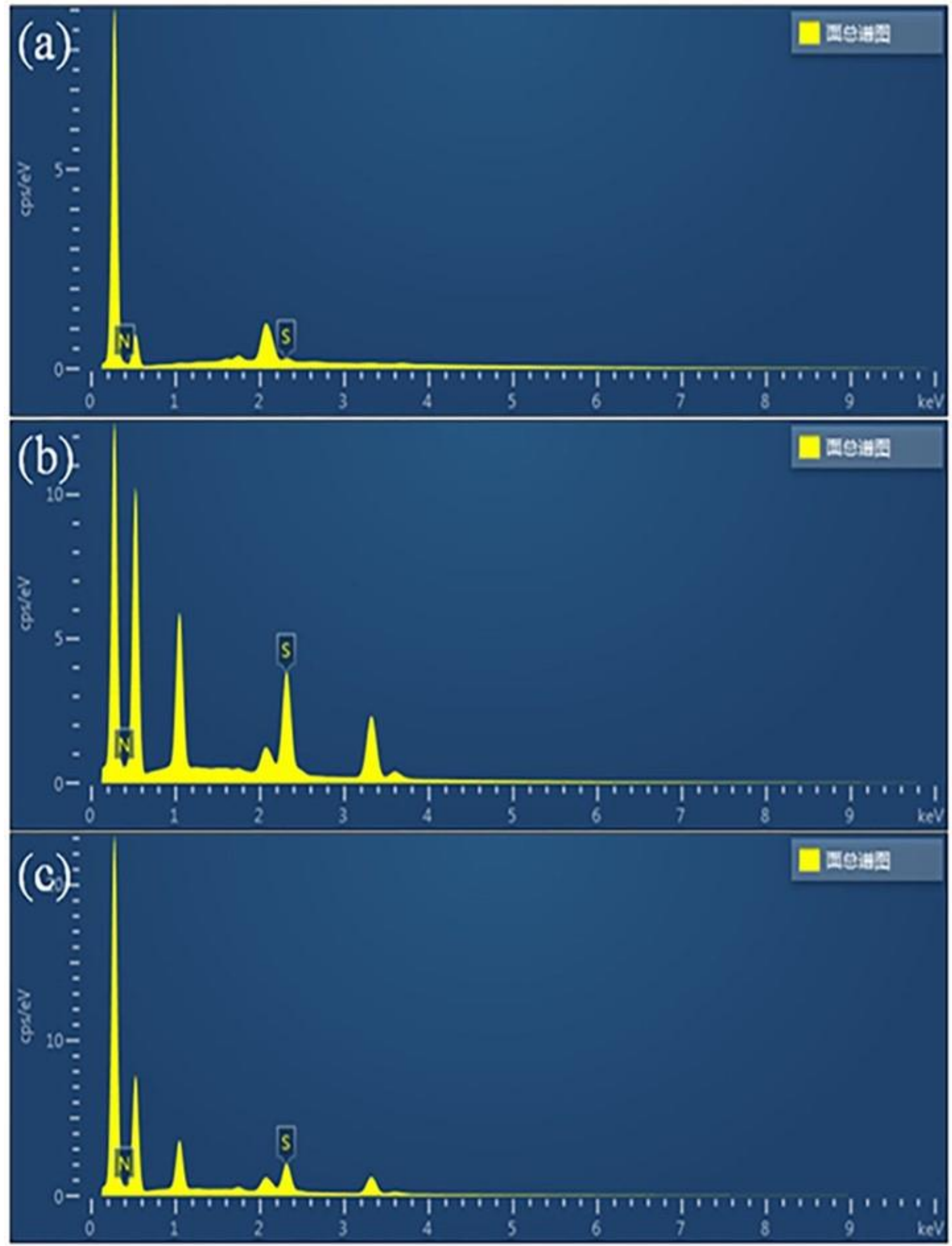

Fig. 5. EDS elemental mapping of composite films, (a): RGO; (b): RGO/LS; and (c): RGO/LS/CM5 


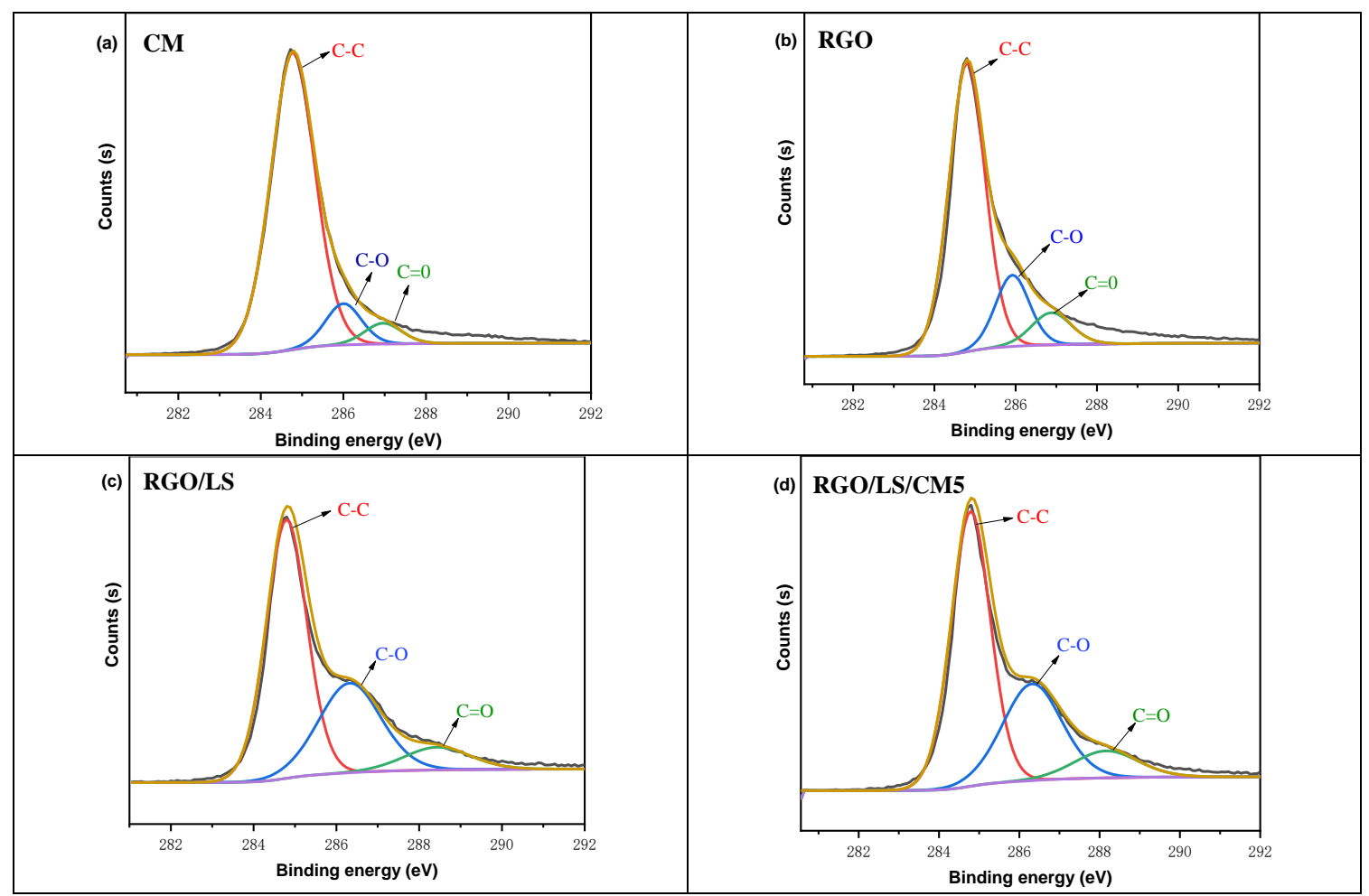

Fig. 6. High-resolution XPS spectra of C 1s peaks for composite films
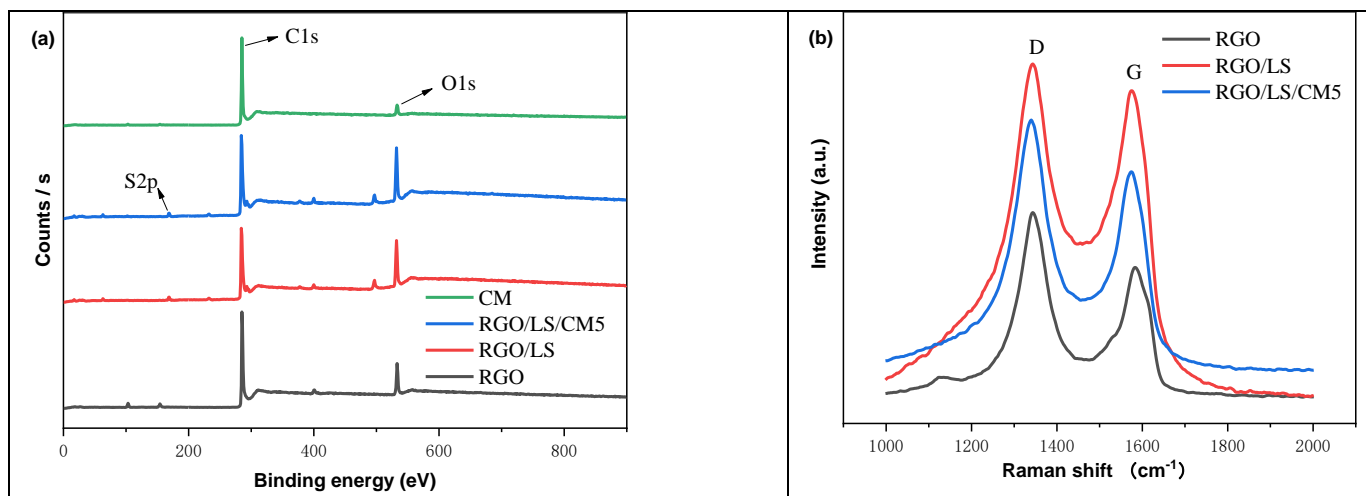

Fig. 7. (a): the whole XPS spectra of CM and composite films; (b) Raman spectra of composite films

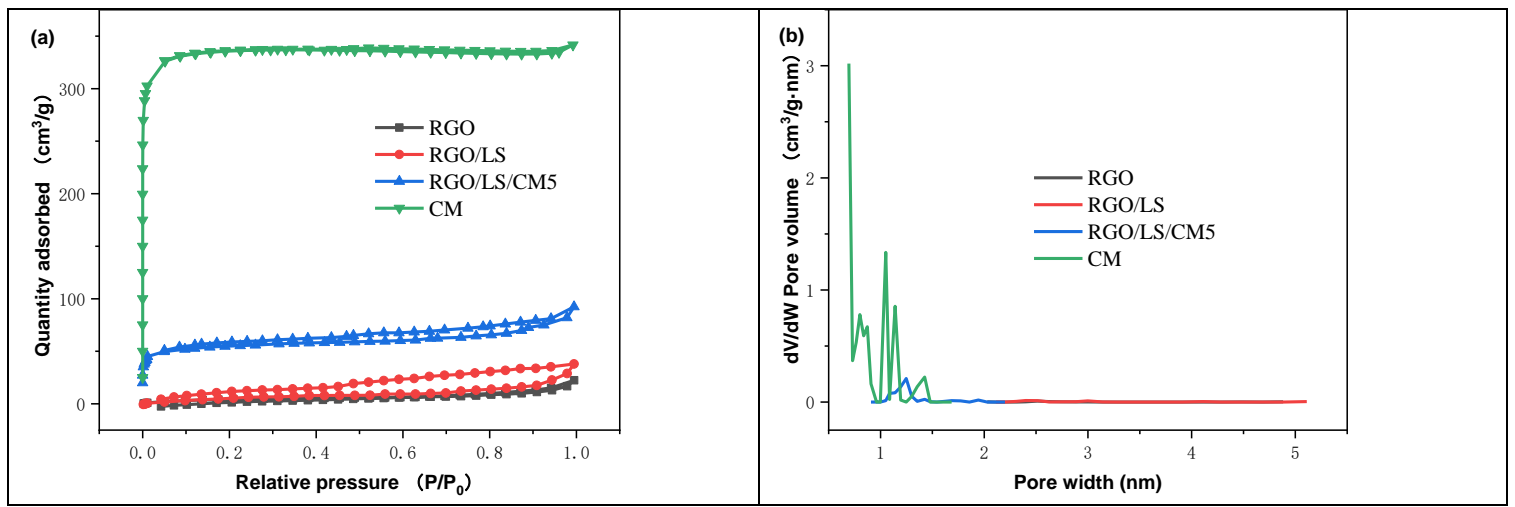

Fig. 8. (a) Nitrogen adsorption/desorption isotherms for all samples; (b) pore size distribution for all samples 
The electrochemical performance of composite film electrodes were investigated in $1.0 \mathrm{M} \mathrm{H}_{2} \mathrm{SO}_{4}$ aqueous electrolyte using a three-electrode system by electrochemical workstation. The GCD curves for all composite film electrodes at a current density of 0.2 $\mathrm{mA} \mathrm{cm} \mathrm{cm}^{-2}$ are shown in Fig. 9a. The shape of curves for all samples was nearly triangular, which indicated that all electrodes had the ideal charge performance (Cheng et al. 2012; $\mathrm{Xu}$ et al. 2017). The area specific capacitance and the specific capacitance were calculated according to Eqs. 1 and 2, respectively, and the capacitance calculation results of the membrane electrodes are shown in Table 2. Compared with RGO electrode $\left(1.7 \mathrm{mg} \mathrm{cm}^{-2}\right)$, the RGO/LS electrode $\left(2.8 \mathrm{mg} \mathrm{cm}^{-2}\right)$ showed longer discharge time, and the area specific capacitance was calculated to be $242.6 \mathrm{mF} \mathrm{cm}^{-2}$ ( specific capacitance of $86.6 \mathrm{~F} \mathrm{~g}^{-1}$ ) based on Eqs. 1 and 2 at the current density of $0.2 \mathrm{~mA} \mathrm{~g}^{-1}$, which was much higher than that (117.9 $\mathrm{mF} \mathrm{cm}^{-2} / 69.3 \mathrm{~F} \mathrm{~g} \mathrm{~g}^{-1}$ ) of the RGO. This was attributed to the oxygenic groups and increased layer spacing with the addition of lignosulfonate. In addition, the RGO/LS/CM5 electrode exhibited the longest discharge time, which had the maximum area ratio capacitance of $641 \mathrm{mF} \mathrm{cm}^{-2}$ (specific capacitance of $178 \mathrm{~F} \mathrm{~g}^{-1}$ ), indicating that the doping of $\mathrm{CM}$ made an enormous contribution to the electrochemical performance. In consideration that the addition of $\mathrm{CM}$ will reduce the flexibility of the composite film to a certain extent, the authors chose the addition amount of $\mathrm{CM}$ to be $5 \mathrm{mg}$; therefore, the authors conducted further tests on the samples RGO, RGO/LS, and RGO/LS/CM5. Moreover, the area specific capacitance of three electrodes can also be clearly seen at the current density of 0.2 to $5 \mathrm{~mA} \mathrm{~g}^{-1}$ from Fig. $9 \mathrm{~b}$. Upon increasing the current density up to $5 \mathrm{~mA} \mathrm{~cm}^{-2}$, the area specific capacitance of sample RGO/LS/CM5 retained about $41.9 \%$ of its original value, which was more than that of sample RGO (29.3\%). This was mainly due to the compact lamellar structure of RGO film.

As shown in Fig. 9c, the CV curves of the RGO electrode at the scan rate of $5 \mathrm{mV}$ $\mathrm{s}^{-1}$ exhibited a nearly rectangular shape, which indicated an ideal double-layer capacitive behaviour (Zhou and Zhai 2016; Chen et al. 2018; Lv et al. 2018); however, the CV curves of the RGO/LS and RGO/LS/CM5 electrodes showed the Faradic peaks in the potential window of 0.4 to $0.7 \mathrm{~V}$, which was due to the reversible redox reaction of $\mathrm{Q} / \mathrm{QH}_{2}$ structure in $\mathrm{LS}\left(\mathrm{QH}_{2} \rightleftharpoons \mathrm{Q}+2 \mathrm{e}^{-}+2 \mathrm{H}^{+}\right)^{1}$. According to previous research, the $\mathrm{Q} / \mathrm{QH} 2$ structure can store and release two electrons and protons during the reversible charging/discharging process, furthermore, the RGO/LS/CM5 electrode showed the largest current and integral area which coincided with the result of the GCD test. The Nyquist plots of electrodes are shown in Fig. 9d. For each curve there was a nearly semi-circle intersecting the real axis in the high frequency region, and the plot was transformed to almost a vertical line with decreasing frequency, as shown in Fig. 9d. The semicircular arc of RGO/LS and $\mathrm{RGO/LS/CM5}$ decreased in size compared with that of RGO, primarily revealing the decrease of the charge-transfer resistance, which was due to the addition of LS and CM. Moreover, the almost vertical shape at the low frequencies indicated an ideal capacitive characteristic of the electrodes. It was obvious that the curves of electrodes RGO/LS and RGO/LS/CM5 were close to vertical line compared with electrode RGO, which suggested RGO/LS and RGO/LS/CM5 with lower resistance have good conductivity. Figures 10a and $\mathrm{b}$ show the GCD curves at different current densities and the $\mathrm{CV}$ curves measured from 0 to $1.0 \mathrm{~V}$ at different scan rates of electrode RGO/LS/CM5. All of the CV curves showed rectangular-like shapes even at high scan rates and the GCD curves were nearly symmetric triangular shape with their corresponding discharging counterparts which further demonstrated the ideal capacitive and fast charge/discharge behavior of the film RGO/LS/CM5. 
Table 1. Physical Properties of all Samples

\begin{tabular}{|l|l|l|l|l|}
\hline Sample & $S_{\text {BET }}\left(\mathrm{m}^{2} \mathrm{~g}^{-1}\right)$ & $S_{\text {mic }}\left(\mathrm{m}^{2} \mathrm{~g}^{-1}\right)$ & $V_{\text {tot }}\left(\mathrm{cm}^{3} \mathrm{~g}^{-1}\right)$ & $V_{\text {mic }}\left(\mathrm{cm}^{3} \mathrm{~g}^{-1}\right)$ \\
\hline CM & 1066.6 & 1056.9 & 0.5238 & 0.5175 \\
\hline RGO & 17.54 & 4.46 & 0.03473 & 0.0013 \\
\hline RGO/LS & 31.9 & 11.33 & 0.05868 & 0.0023 \\
\hline RGO/LS/CM5 & 178.65 & 153.41 & 0.1428 & 0.07546 \\
\hline
\end{tabular}

Table 2. Capacitive Performances of All Membrane Electrodes

\begin{tabular}{|l|l|l|l|l|}
\hline Sample & Mass $(\mathrm{mg})$ & Area $\left(\mathrm{cm}^{-2}\right)$ & $C_{\mathrm{m}}\left(\mathrm{F} \mathrm{g}^{-1}\right)$ & $C_{\mathrm{s}}\left(\mathrm{mF} \mathrm{cm}{ }^{-2}\right)$ \\
\hline RGO & 1.7 & 1 & 69.3 & 117.9 \\
\hline RGO/LS & 2.8 & 1 & 86.6 & 242.6 \\
\hline RGO/LS/CM1 & 3 & 1 & 99 & 297.3 \\
\hline RGO/LS/CM3 & 3.3 & 1 & 153.6 & 460.9 \\
\hline RGO/LS/CM5 & 3.6 & 1 & 178 & 641 \\
\hline
\end{tabular}

Table 3. Literature on Graphene-based Electrodes for Supercapacitor Application

\begin{tabular}{|l|l|l|l|}
\hline Electrode & Capacitance & Electrolyte & Ref. \\
\hline $\begin{array}{l}\text { Graphene nanosheet/carbon } \\
\text { black }\end{array}$ & $175.0 \mathrm{~F} \mathrm{~g}^{-1}\left(10 \mathrm{mV} \mathrm{s}^{-1}\right)$ & $6 \mathrm{M} \mathrm{KOH}$ & Yan et al. 2010 \\
\hline Graphene-cellulose paper & $\begin{array}{l}120 \mathrm{~F} \mathrm{~g}^{-1} / 81 \mathrm{mF} \mathrm{cm}^{-2} \\
\left(1 \mathrm{mV} \mathrm{s}^{-1}\right)\end{array}$ & $1 \mathrm{M} \mathrm{H}_{2} \mathrm{SO}_{4}$ & Weng et al. 2011 \\
\hline Graphene/onion-like carbon & $143 \mathrm{~F} \mathrm{~g}^{-1}\left(0.2 \mathrm{~A} \mathrm{~g}^{-1}\right)$ & $1 \mathrm{M} \mathrm{H}_{2} \mathrm{SO}_{4}$ & Sun et al. 2011 \\
\hline Peanut shell/Few-layer graphene & $186 \mathrm{~F} \mathrm{~g}^{-1}\left(0.5 \mathrm{~A} \mathrm{~g}^{-1}\right)$ & $1 \mathrm{M} \mathrm{H}_{2} \mathrm{SO}_{4}$ & Purkait et al. 2017 \\
\hline RGO/LS/CM & $\begin{array}{l}178 \mathrm{~F} \mathrm{~g}^{-1} / 641 \mathrm{mF} \mathrm{cm}^{-2} \\
\left(0.2 \mathrm{~mA} \mathrm{~cm}^{-2}\right)\end{array}$ & $1 \mathrm{M} \mathrm{H}_{2} \mathrm{SO}_{4}$ & This work \\
\hline
\end{tabular}
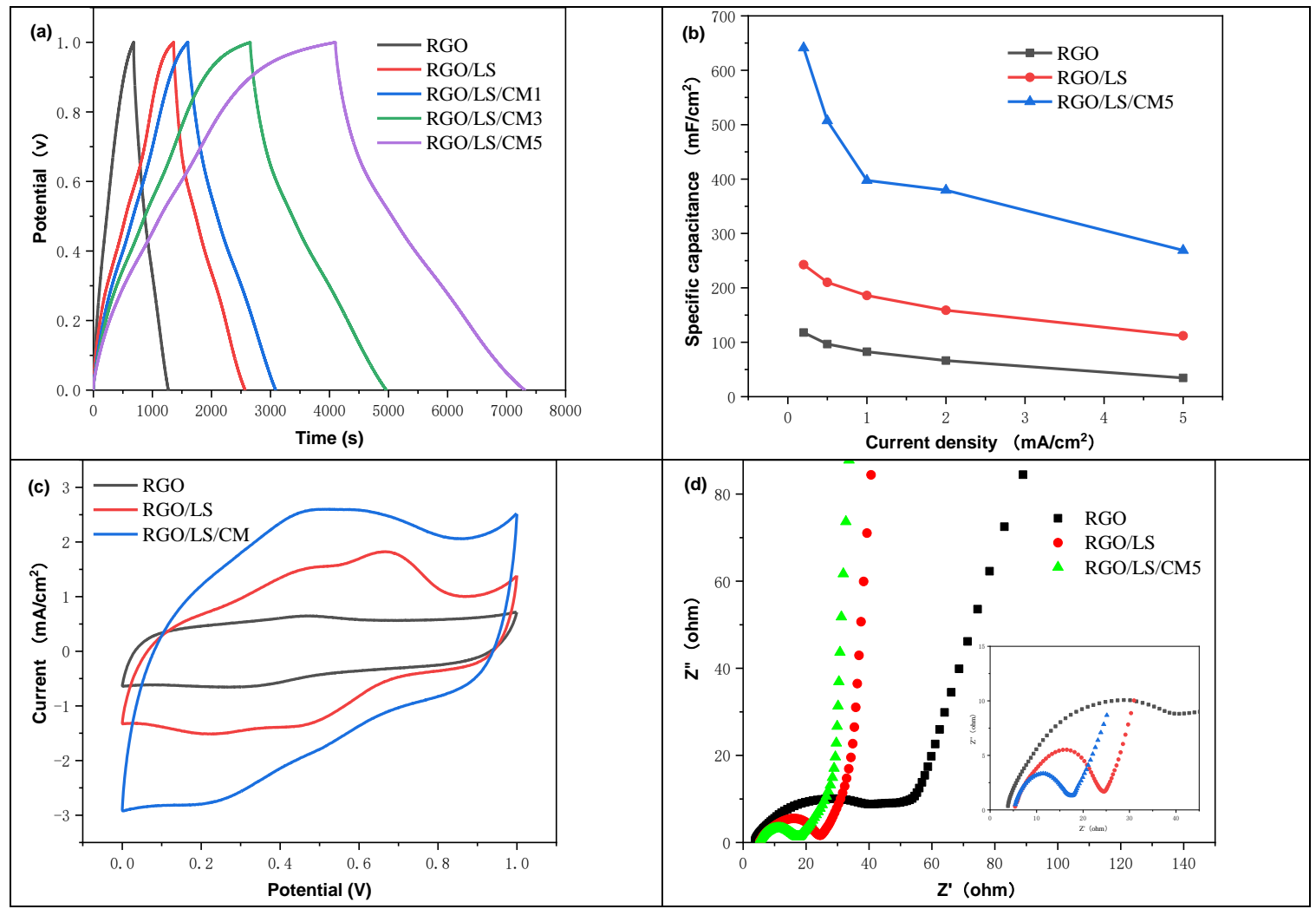

Fig. 9. (a through d) 

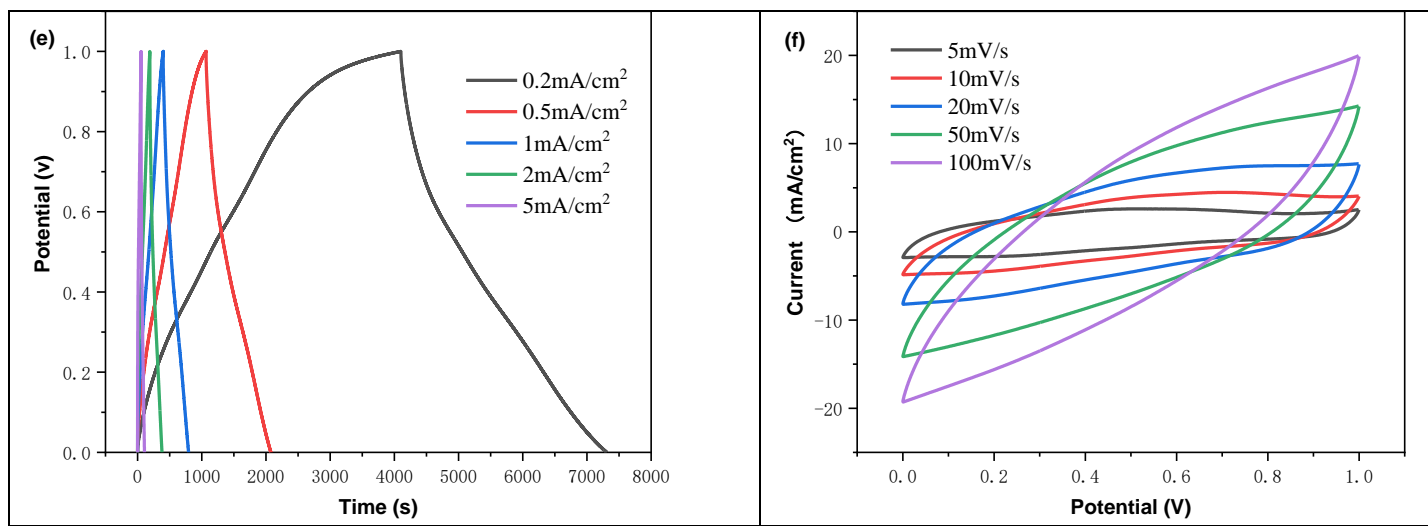

Fig. 9. (a) GCD curves of all electrodes at the density of $0.2 \mathrm{~mA} \mathrm{~cm}^{-2}$; (b) specific capacitance of all electrodes measured with different current densities; (c) CV curves of all electrodes at the scan rate of $5 \mathrm{mV} \mathrm{s}^{-1}$; (d) Nyquist plot of all electrodes (inset: enlarged high-frequency region of the Nyquist plot); (e) GCD curves of RGO/LS/CM5 at different current density; and (f) CV curves of $R G O / L S / C M 5$ at different scan rates

\section{CONCLUSIONS}

1. A metal-free and flexible film electrode based on reduced graphene oxide (RGO), lignosulfonate (LS), and carbon microspheres (CM) was prepared by a simple vacuum filtration method. The addition of renewable biomass could lead to low-cost electrode materials with improved safety, non-toxicity, and sustainability.

2. Lignosulfonate combined with RGO sheets by $\pi-\pi$ conjugation increased the interlayer spacing of RGO sheets. The addition of a certain amount of CM greatly increased the specific surface area of the composite film without damaging the flexibility of film RGO/LS/CM5. The specific capacitance of the RGO/LS/CM5 film electrode was calculated to be $641 \mathrm{mF} \mathrm{cm}^{-2}$ (specific capacitance of $178 \mathrm{~F} \mathrm{~g}^{-1}$ ) at $0.2 \mathrm{~mA} \mathrm{~cm}^{-2}$, which was much higher than that of RGO film electrode $\left(118 \mathrm{mF} \mathrm{cm}^{-2} / 69 \mathrm{~F} \mathrm{~g}^{-1}\right)$.

3. This work provides a promising route for metal-free, low-cost, and flexible supercapacitor electrode based on graphene and biomass material.

\section{ACKNOWLEDGMENTS}

This work was supported by the National Natural Science Foundation of China (Grant No. 21671021), State Key Research Project (2017YFD0600203), and Scientific and Technological Innovation Projects by Shandong Province (2019JZZY020223).

\section{REFERENCES CITED}

Al-Gaashani, R., Najjar, A., Zakaria, Y., Mansour, S., and Atieh, M. A. (2019). "XPS and structural studies of high quality graphene oxide and reduced graphene oxide prepared by different chemical oxidation methods," Ceramics International 45(11), 14439-14448. DOI: 10.1016/j.ceramint.2019.04.165 
Beidaghi, M., and Wang, C. (2012). "Micro-supercapacitors based on interdigital electrodes of reduced graphene oxide and carbon nanotube composites with ultrahigh power handling performance," Advanced Functional Materials 22(21), 4501-4510. DOI: $10.1002 /$ adfm.201201292

Chen, L., Chen, L., Ai, Q., Li, D., Si, P., Feng, J., Zhang, L., Li, Y., Lou, J., and Ci, L. (2018). "Flexible all-solid-state supercapacitors based on freestanding, binder-free carbon nanofibers@polypyrrole@graphene film," Chemical Engineering Journal 334, 184-190. DOI: 10.1016/j.cej.2017.10.038

Chen, X., Chen, X., Zhang, F., Yang, Z., and Huang, S. (2013). "One-pot hydrothermal synthesis of reduced graphene oxide/carbon nanotube $/ \alpha-\mathrm{Ni}(\mathrm{OH})_{2}$ composites for high performance electrochemical supercapacitor," Journal of Power Sources 243, 555561. DOI: 10.1016/j.jpowsour.2013.04.076

Cheng, Y., Lu, S., Zhang, H., Varanasi, C. V., and Liu, J. (2012). "Synergistic effects from graphene and carbon nanotubes enable flexible and robust electrodes for highperformance supercapacitors," Nano Letters 12(8), 4206-4211. DOI: $10.1021 / \mathrm{nl} 301804 \mathrm{c}$

Chen, C., Wang, X., Li, M., Fan, Y., and Sun, R. (2018). "Humidity sensor based on reduced graphene oxide/lignosulfonate composite thin-film," Sensors and Actuators B: Chemical 255, 1569-1576. DOI: 10.1016/j.snb.2017.08.168

Dang, Y., Ren, S., Liu, G., Cai, J., Zhang, Y., and Qiu, J. (2016). "Electrochemical and capacitive properties of carbon dots/reduced graphene oxide supercapacitors," Nanomaterials 6(11), article no. 212. DOI: 10.3390/nano6110212

Díez, N., Qiao, M., Gómez-Urbano, J. L., Botas, C., Carriazo, D., and Titirici, M. M. (2019). "High density graphene-carbon nanosphere films for capacitive energy storage," Journal of Materials Chemistry A 7(11), 6126-6133. DOI: $10.1039 / \mathrm{c} 8 \mathrm{ta} 12050 \mathrm{a}$

Feng, H., Xie, P., Xue, S., Li, L., Hou, X., Liu, Z., Wu, D., Wang, L., and Chu, P. K. (2018). "Synthesis of three-dimensional porous reduced graphene oxide hydrogel/carbon dots for high-performance supercapacitor," Journal of Electroanalytical Chemistry 808, 321-328. DOI: 10.1016/j.jelechem.2017.12.046

Ferrari, A. C., Meyer, J. C., Scardaci, V., Casiraghi, C., Lazzeri, M., Mauri, F., Piscanec, S., Jiang, D., Novoselov, K. S., Roth, S., and Geim, A. K. (2006). "Raman spectrum of graphene and graphene layers," Physical Review Letters 97(18), article ID 187401. DOI: 10.1103/PhysRevLett.97.187401

Gao, H., and Duan, H. (2015). "2D and 3D graphene materials: Preparation and bioelectrochemical applications" Biosensors and Bioelectronics 65, 404-419. DOI: 10.1016/j.bios.2014.10.067

He, X., Zhang, N., Shao, X., Wu, M., Yu, M., and Qiu, J. (2016), “A layered-templatenanospace-confinement strategy for production of corrugated graphene nanosheets from petroleum pitch for supercapacitors," Chemical Engineering Journal 297(C), 121-127. DOI: 10.1016/j.cej.2016.03.153

Hummers, W. S., and Offeman, R. E. (1958). "Preparation of graphitic oxide," Journal of the American Chemical Society 80(6), article no. 1339. DOI: 10.1021/ja01539a017

Jin, Y., Chen, H., Chen, M., Liu, N., and Li, Q. (2013). "Graphene-patched CNT/MnO2 nanocomposite papers for the electrode of high-performance flexible asymmetric supercapacitors," ACS Applied Materials \& Interfaces 5(8), 3408-3416. DOI: $10.1021 / \mathrm{am} 400457 \mathrm{x}$ 
Li, F., Wang, X., and Sun, R. (2017). "A metal-free and flexible supercapacitor based on redox-active lignosulfonate functionalized graphene hydrogels," Journal of Materials Chemistry A 5(39), 20643-20650. DOI: 10.1039/c7ta03789a

Li, X., Tang, Y., Song, J., Yang, W., Wang, M., Zhu, C., Zhao, W., Zheng, J., and Lin, Y. (2018). "Self-supporting activated carbon/carbon nanotube/reduced graphene oxide flexible electrode for high performance supercapacitor," Carbon 129(C), 236-244. DOI: 10.1016/j.carbon.2017.11.099

Liu, X., Zou, S., Liu, K., Lv, C., Wu, Z., Yin, Y., Liang, T., and Xie, Z. (2018). "Highly compressible three-dimensional graphene hydrogel for foldable all-solid-state supercapacitor," Journal of Power Sources 384, 214-222. DOI:

10.1016/j.jpowsour.2018.02.087

Lv, H., Yuan, Y., Xu, Q., Liu, H., Wang, Y., and Xia, Y. (2018). "Carbon quantum dots anchoring $\mathrm{MnO} 2$ /graphene aerogel exhibits excellent performance as electrode materials for supercapacitor," Journal of Power Sources 398, 167-174. DOI: 10.1016/j.jpowsour.2018.07.059

Maiti, U. N., Lim, J., Lee, K. E., Lee, W. J., and Kim, S. O. (2014). “Three-dimensional shape engineered, interfacial gelation of reduced graphene oxide for high rate, large capacity supercapacitors," Advanced Materials 26(4), 615-619. DOI: 10.1002/adma.201303503

Malard, L. M., Pimenta, M. A., Dresselhaus, G., and Dresselhaus, M. S. (2009). "Raman spectroscopy in graphene," Physics Reports 473(5-6), 51-87. DOI: 10.1016/j.physrep.2009.02.003

Nagaraju, D. H., Rebis, T., Gabrielsson, R., Elfwing, A., Milczarek, G., and Inganäs, O. (2014). "Charge storage capacity of renewable biopolymer/conjugated polymer interpenetrating networks enhanced by electroactive dopants," Advanced Energy Materials 4(1), Article ID 1300443. DOI: 10.1002/aenm.201300443

Peng, Z., Wang, C., Zhang, Z., and Zhong, W. (2019). "Synthesis and enhancement of electroactive biomass/polypyrrole hydrogels for high performance flexible all-solidstate supercapacitors," Advanced Materials Interfaces 6(23), Article ID 1901393. DOI: 10.1002/admi.201901393

Purkait, T., Singh, G., Singh, M., Kumar, D., and Dey, R. S. (2017). "Large area fewlayer graphene with scalable preparation from waste biomass for high-performance supercapacitor," Scientific Reports 7(1), 1-14. DOI: 10.1038/s41598-017-15463-w

Qian, W., Cui, X., Hao, R., Hou, Y., and Zhang, Z. (2011). "Facile preparation of nitrogen-doped few-layer graphene via supercritical reaction," ACS Applied Materials \& Interfaces 3(7), 2259-2264. DOI: 10.1021/am200479d

Rębiś, T., and Milczarek, G. (2016). "A comparative study on the preparation of redox active bioorganic thin films based on lignosulfonate and conducting polymers," Electrochimica Acta 204, 108-117. DOI: 10.1016/j.electacta.2016.04.061

Sekar, P., Anothumakkool, B., and Kurungot, S. (2015). “3D polyaniline porous layer anchored pillared graphene sheets: Enhanced interface joined with high conductivity for better charge storage applications," ACS Applied Materials \& Interfaces 7(14), 7661-7669. DOI: 10.1021/acsami.5b00504

Shang, T., Ren, R., Zhu, Y., and Jin, X. (2015). “Oxygen- and nitrogen-co-doped activated carbon from waste particleboard for potential application in highperformance capacitance," Electrochimica Acta 163(C), 32-40. DOI: 10.1016/j.electacta.2015.02.147 
Sun, Y., Wu, Q., Xu, Y., Bai, H., Li, C., and Shi, G. (2011). "Highly conductive and flexible mesoporous graphitic films prepared by graphitizing the composites of graphene oxide and nanodiamond," Journal of Materials Chemistry 21(20), 71547160. DOI: 10.1039/c0jm04434b

Sun, H., You, X., Deng, J., Chen, X., Yang, Z., Ren, J., and Peng, H. (2014). "Novel graphene/carbon nanotube composite fibers for efficient wire-shaped miniature energy devices," Advanced Materials 26(18), 2868-2873. DOI: 10.1002/adma.201305188

Unnikrishnan, B., Wu, C., Chen, I. P., Chang, H., Lin, C., and Huang, C. (2016). "Carbon dot-mediated synthesis of manganese oxide decorated graphene nanosheets for supercapacitor application," ACS Sustainable Chemistry \& Engineering 4(6), 30083016. DOI: 10.1021/acssuschemeng.5b01700

Wang, G., Sun, X., Lu, F., Sun, H., Yu, M., Jiang, W., Liu, C., and Lian, J. (2012). "Flexible pillared graphene-paper electrodes for high-performance electrochemical supercapacitors," Small 8(3), 452-459. DOI: 10.1002/smll.201101719

Wei, L., Deng, W., Li, S., Wu, Z., Cai, J., and Luo, J. (2021). "Sandwich-like chitosan porous carbon Spheres/MXene composite with high specific capacitance and rate performance for supercapacitors," Journal of Bioresources and Bioproducts, Early availability. DOI: 10.1016/j.jobab.2021.10.001

Weng, Z., Su, Y., Wang, D., Li, F., Du, J., and Cheng, H. (2011). "Graphene-cellulose paper flexible supercapacitors," Advanced Energy Materials 1(5), 917-922. DOI: 10.1002/aenm.201100312

Wu, D., and Zhong, W. (2019). "A new strategy for anchoring a functionalized graphene hydrogel in a carbon cloth network to support a lignosulfonate/polyaniline hydrogel as an integrated electrode for flexible high areal-capacitance supercapacitors," Journal of Materials Chemistry A 7(10), 5819-5830. DOI: 10.1039/c8ta11153g

Xiong, C., Zhong, W., Zou, Y., Luo, J., and Yang, W. (2016). "Electroactive biopolymer/graphene hydrogels prepared for high-performance supercapacitor electrodes," Electrochimica Acta 211, 941-949. DOI: 10.1016/j.electacta.2016.06.117

$\mathrm{Xu}$, L., Cheng, C., Yao, C., and Jin, X. (2020). "Flexible supercapacitor electrode based on lignosulfonate-derived graphene quantum dots/graphene hydrogel," Organic Electronics 78, article ID 105407. DOI: 10.1016/j.orgel.2019.105407

Xu, L., Jia, M., Li, Y., Jin, X., and Zhang, F. (2017). "High-performance MnO2deposited graphene/activated carbon film electrodes for flexible solid-state supercapacitor," Scientific Reports 7(1), article ID 12857. DOI: 10.1038/s41598-01711267-0

Xu, L., Li, Y., Jia, M., Zhao, Q., Jin, X., and Yao, C. (2017). "Synthesis and characterization of free-standing activated carbon/reduced graphene oxide film electrodes for flexible supercapacitors," RSC Advances 7(71), 45066-45074. DOI: $10.1039 / \mathrm{c} 7 \mathrm{ra07459j}$

Xu, Z., Li, Z., Holt, C. M. B., Tan, X., Wang, H., Amirkhiz, B. S., Stephenson, T., and Mitlin, D. (2012). "Electrochemical supercapacitor electrodes from sponge-like graphene nanoarchitectures with ultrahigh power density," Journal of Physical Chemistry Letters 3(20), 2928-2933. DOI: 10.1021/jz301207g

Yan, J., Wei, T., Shao, B., Ma, F., Fan, Z., Zhang, M., Zheng, C., Shang, Y., Qian, W., and Wei, F. (2010). "Electrochemical properties of graphene nanosheet/carbon black composites as electrodes for supercapacitors," Carbon 48(6), 1731-1737. DOI: 10.1016/j.carbon.2010.01.014 
Yan, J., Liu, J., Fan, Z., Wei, T., and Zhang, L. (2012). "High-performance supercapacitor electrodes based on highly corrugated graphene sheets," Carbon 50(6), 2179-2188. DOI: 10.1016/j.carbon.2012.01.028

Yang, D., Velamakanni, A., Bozoklu, G., Park, S., Stoller, M., Piner, R. D., Stankovich, S., Jung, I., Field, D. A., Ventrice, C. A., and Ruoff, R. S. (2009). "Chemical analysis of graphene oxide films after heat and chemical treatments by X-ray photoelectron and micro-Raman spectroscopy," Carbon 47(1), 145-152. DOI: 10.1016/j.carbon.2008.09.045

You, B., Wang, L., Yao, L., and Yang, J. (2013). “Three dimensional N-doped grapheneCNT networks for supercapacitor," Chemical Communications 49(44), 5016-5018. DOI: $10.1039 / \mathrm{c} 3 \mathrm{cc} 41949 \mathrm{e}$

Yu, D., and Dai, L. (2009). "Self-assembled graphene/carbon nanotube hybrid films for supercapacitors," The Journal of Physical Chemistry Letters 1(2), 467-470. DOI: 10.1021/jz9003137

Zhang, X., Wang, J., Liu, J., Wu, J., Chen, H., and Bi, H. (2017). "Design and preparation of a ternary composite of graphene oxide/carbon dots/polypyrrole for supercapacitor application: Importance and unique role of carbon dots," Carbon 115(C), 134-146. DOI: 10.1016/j.carbon.2017.01.005

Zhao, G., Jiang, L., He, Y., Li, J., Dong, H., Wang, X., and Hu, W. (2011). "Sulfonated graphene for persistent aromatic pollutant management," Advanced Materials 23(34), 3959-3963. DOI: 10.1002/adma.201101007

Zhao, M., Zhang, Q., Huang, J., Tian, G., Nie, J., Peng, H., and Wei, F. (2014). "Unstacked double-layer templated graphene for high-rate lithium-sulphur batteries," Nature Communications 5, Article ID 3410. DOI: 10.1038/ncomms4410

Zhao, H., Wang, W., Lu, Q., Lin, T., Lin, Q., and Yang, H. (2015). "Preparation and application of porous nitrogen-doped graphene obtained by co-pyrolysis of lignosulfonate and graphene oxide," Bioresource Technology 176, 106-111. DOI: 10.1016/j.biortech.2014.11.035

Zhou, H., and Zhai, H. (2016). "A highly flexible solid-state supercapacitor based on the carbon nanotube doped graphene oxide/polypyrrole composites with superior electrochemical performances," Organic Electronics 37, 197-206. DOI: 10.1016/j.orgel.2016.06.036

Article submitted: November 14, 2021; Peer review completed: January 9, 2022; Revised version received and accepted: January 19, 2022; Published: January 24, 2022.

DOI: 10.15376/biores.17.1.1729-1744 